\title{
Katrina, climate change and the poor
}

A lthough no one could argue that it was the SUVs driven by the affluent folk now returning to the Uptown district of New Orleans that drew Katrina's fury upon their city, it is becoming clearer that climate change resulting from the greenhouse gas emissions of the industrialized world is resulting in an increasing severity of hurricanes in this and other areas of the world. Warming of the oceans over the past 35 years has been accompanied by an $80 \%$ increase in category 4 and $5 \mathrm{cy}-$ clones worldwide (and a $57 \%$ increase in the Gulf of Mexico over the past 20 years).

And so, while New Orleans drains, revealing the ruined homes of those who lived on the city's most vulnerable ground - the poor, pigmented and powerless - let us reflect on an important fact: different populations are not affected equally by environmental disaster. The effects of severe weather events disproportionately affect the poor and powerless, who have fewer resources to respond to calamity. In New Orleans, helicopters airlifted victims from the roofs of private hospitals while charity hospitals pleaded desperately for help. Those in well-appointed neighbourhoods escaped in their own cars; the poor, predominantly black, citizens from low-lying areas were typically not so lucky.

If the unequal distribution of safety along social and racial lines in New Orleans has shocked us, we should not forget that in many corners of the world marginalized populations suffer disproportionately both from environmental disaster and from gradual climate change. In part, this is because the fruits of science and technology are not distributed equally. In the failure to maintain the levees despite the disaster-modelling of engineers, in the failure to install a tidal wave warning system in earthquake-prone regions (except those adjacent to our developed world), in the failure to advance a truly global pandemic-preparedness plan against avian influenza, similar mechanisms of selfishness and short-sightedness are at work.

Short-sightedness certainly characterizes the failure to seriously address the United Nations Millennium Goals for the environment. Even the slight increase in global temperature that has occurred over the past 30 years results annually in an additional 150000 deaths and 5.5 million disabil- ity-adjusted life years lost. These rates will double in the next 20 years, mainly because of diarrheal diseases and malnutrition in the developing world. While we in the developed world can survive the effects of climate change by turning up our air conditioners, protecting ourselves with DEET against West Nile virus, and providing subsidies for drought-stricken farmers, for the world's poor a single season of flood or drought is enough to trigger widescale famine. Even in Canada we see an unequal burden resulting from the environmental degradation wrought by global warming: for example, the change in distribution of sea ice and the destruction of northern ecosystems mean that Inuit in Nunavik and Labrador cannot travel at certain times of the year to hunt and to access potable water. ${ }^{2}$

The United Nations Millennium Goals regarding the environment include targets for access to potable water, sanitation and adequate housing. In all areas there is inadequate developed country investment; few gains are being made, and there is even some slippage. Only $42 \%$ of the population of sub-Saharan Africa has access to drinking water, only $50 \%$ of the world's population has access to adequate sanitation facilities, one third of the global urban population live in slums (about 1 billion people worldwide) which, like those in New Orleans, are characterized by overcrowding, unemployment, lack of security of tenure and high rates of violence.

The collective failures revealed by the disaster in New Orleans go far beyond inadequacies in disaster preparedness and recovery; they are the failures of all of us to seriously address global environmental threats and our unwillingness to more equitably distribute wealth and health. CMAF

\section{References}

1. Webster PJ, Holland GJ, Curry JA, Chang HR. Changes in tropical cyclone number, duration, and intensity in a warming environment. Science 2005;309(5742):1844-6.

2. Furgal CM, Martin D, Gosselin P, Viau A, Nunavik Regional Board of Health and Social Services/Nunavik Nutrition and Health Committee LIA. Climate change and bealth in Nunavik and Labrador: what we know from science and Innit knowledge. Beauport (Que): WHO/PAHO Collaborating Centre in Environmental and Occupational Health Impact Assessment and Surveillance, Centre hospitalier universitaire de Québec; 2002. 